[3] Chehade L, Jaafar ZA, El Masri D, Zmerly H, Kreidieh D, Tannir H, Itani L, and El Ghoch, M. 2019. Lifestyle Modification in Rheumatoid Arthritis: Dietary and Physical Activity Recommendations Based on Evidence. Current rheumatology reviews, 15(3), pp.209-214.

[4] Marchand NE, Chiu Y-H, Yoshida K, Malspeis S, Sparks JA, Costenbader K, et al. Threshold Level for Long-term Healthy Diet Adherence to Reduce the Risk of Rheumatoid Arthritis Among Women in a Prospective Cohort Using a Marginal Structural Model Approach.:25

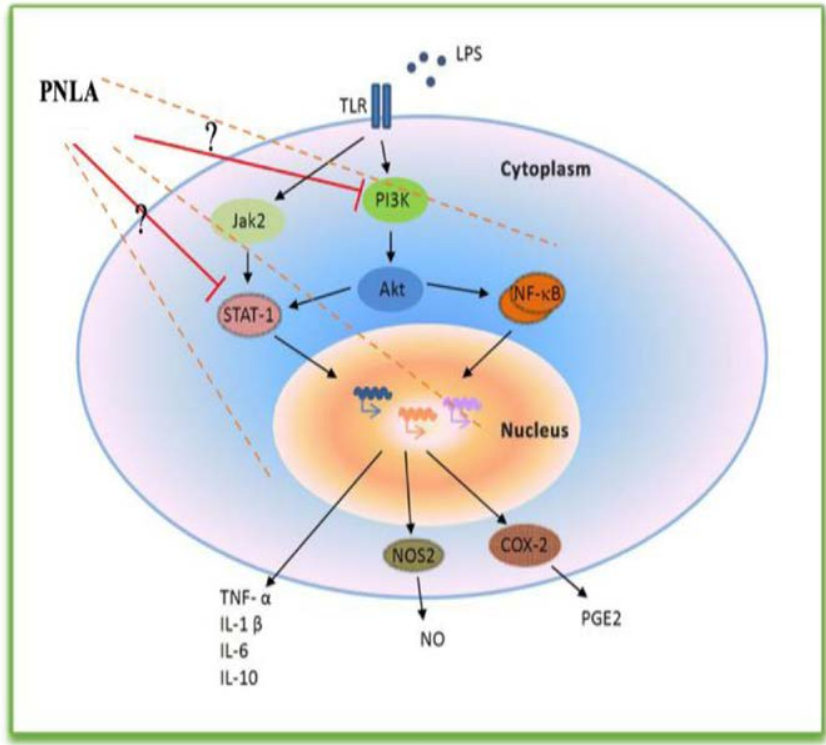

Diagram 1.

Disclosure of Interests: None declared

DOI: 10.1136/annrheumdis-2021-eular.747

\section{POS0347 SPECIFIC MITO-NUCLEAR INTERACTIONS AND MT16519C VARIANT AS PREDICTIVE BIOMARKERS FOR THE RAPIDLY PROGRESSIVE OSTEOARTHRITIS OF THE KNEE. DATA FROM THE OSTEOARTHRITIS INITIATIVE}

A. Durán-Sotuela ${ }^{1}$, M. Fernandez-Moreno ${ }^{1}$, M. E. Vazquez Mosquera ${ }^{1}$, P. RamosLouro' ${ }^{1}$, A. Dalmao-Fernandez ${ }^{1}$, S. Relaño-Fernandez ${ }^{1}$, V. Suárez-Ulloa ${ }^{2}$, V. Balboa-Barreiro ${ }^{3}$, N. Oreiro ${ }^{1}$, J. Vázquez García ${ }^{1}$, F. J. Blanco ${ }^{1}$, I. RegoPerez ${ }^{1}$ on behalf of Grupo de investigación en Reumatología (GIR). ${ }^{1}$ Instituto de Investigación Biomédica de A Coruña (INIBIC). Complexo Hospitalario Universitario de A Coruña (CHUAC), Sergas. Universidade da Coruña., Servicio de Reumatología, A Coruña, Spain; ${ }^{2}$ Instituto de Investigación Biomédica de A Coruña (INIBIC). Complexo Hospitalario Universitario de A Coruña (CHUAC), Sergas. Universidade da Coruña., Plataforma de Bioinformática, A Coruña, Spain: ${ }^{3}$ Instituto de Investigación Biomédica de A Coruña (INIBIC). Complexo Hospitalario Universitario de A Coruña (CHUAC), Sergas. Universidade da Coruña., Unidad de apoyo a la investigación, A Coruña, Spain

Background: The early identification of patients with rapid progressive osteoarthritis (RPOA) could allow the implementation of prevention strategies and their inclusion in clinical trials. Polymorphisms in nuclear and mitochondrial DNA (mtDNA) have been associated with OA. Preliminary analyses by our group showed nuclear single nucleotide polymorphism (nSNP) rs12107036 of TP63 as a potential risk factor for RPOA of the knee.

Objectives: i) To analyze interactions between mtDNA haplogroups and rs12107036 ii) To apply Next Generation Sequencing (NGS) to discover novel mitochondrial variants to construct predictive models of RPOA of the knee.

Methods: 1102 Caucasian subjects from the OAI were classified as follows: i) Rapid progressors $(\mathrm{N}=255)$, baseline $\mathrm{KL}$ grade $0-1$ or 2 in at least one knee, that increases up to $K L \geq 3$ or 4 respectively during 48 -month follow-up. ii) Non-rapid progressors $(\mathrm{N}=847)$, with the same baseline characteristics as rapid progressors, but with slower or no evolution over time.

mtDNA haplogroups and rs 12107036 were assigned by mini-sequencing techniques. Novel mtDNA variants were studied by NGS. Statistical analyses included chi-square tests and generalized estimating equations. Relative excess risk due to interaction (RERI) and attributable proportion (AP) were evaluated for the additive interaction between mtDNA clusters and nSNP rs12107036. A nomogram for the estimation of the risk of RPOA was also developed. Analyses were performed using SPSS Statistics v24 and epi.R package included in R software v3.6.3.
Results: Chi-square analyses revealed an increased risk of RPOA in patients with the allele $\mathrm{G}$ of rs12107036 and mtDNA cluster UK (OR 2,013; $p=0,001$ ). An excess of $70,3 \%$ of RERI between nSNP rs 12107036 and mtDNA clusters was detected, indicating that $47,1 \%$ (AP) of the risk is attributable to this interaction, therefore harboring both genetic factors increase the risk of RPOA up to 4,7 times compared to harboring just one. mtDNA sequencing revealed the variant $m t 16519$ overrepresented in rapid-progressors (OR 1,620; $p=0,002$ ).

Table 1 shows the predictive model for the risk of RPOA. The interaction between the allele $\mathrm{G}$ of rs 12107036 and mtDNA cluster KU (OR 1,727; $p=0,036)$, in addition to the variant $\mathrm{mt} 16519 \mathrm{C}$ (OR 1,690; $p=0,003$ ), showed a significant association with the RPOA phenotype regardless of age, BMI, contralateral knee OA, previous injury and WOMAC pain. Image 1 displays the nomogram for predicting risk of RPOA; as an example, a 70 year old male, with a BMI of 28 , WOMAC pain score of 10 , contralateral OA and presence of both mito-nuclear interaction and $\mathrm{mt} 16519 \mathrm{C}$, has a risk of RPOA of 0,7 .

Conclusion: mtDNA genetic variants are useful, not only as modulators of the influence of specific nuclear polymorphisms on the risk of developing RPOA, but also as candidate genetic biomarkers of this phenotype.

Table 1. Predictive model for the risk of RPOA phenotype

\begin{tabular}{|c|c|c|c|c|}
\hline Variable & p-value & OR & $\min 95 \% \mathrm{Cl}$ & MAX $95 \% \mathrm{Cl}$ \\
\hline \multicolumn{5}{|c|}{ Clinical and genetic variables } \\
\hline Age & $<0,001^{\#}$ & 1,056 & 1,038 & 1,074 \\
\hline Female & 0,143 & 1,260 & 0,925 & 1,718 \\
\hline BMI & $<0,001^{\#}$ & 1,065 & 1,030 & 1,101 \\
\hline Contralateral OA & $<0,001^{\#}$ & 1,927 & 1,413 & 2,626 \\
\hline Previous Injury & $<0,001^{\#}$ & 1,770 & 1,293 & 2,422 \\
\hline WOMAC pain & $0,001^{\#}$ & 1,097 & 1,039 & 1,159 \\
\hline rs $12107036 \mathrm{G}$ & 0,172 & 1,226 & 0,915 & 1,643 \\
\hline \multicolumn{4}{|l|}{ mtDNA Clusters ${ }^{s}$} & 2,375 \\
\hline Others & 0,803 & 0,921 & 0,482 & 1,760 \\
\hline TJ & 0,482 & 1,209 & 0,712 & 2,052 \\
\hline UK & 0,136 & 0,698 & 0,435 & 1,120 \\
\hline HV & & & & Reference \\
\hline \multicolumn{5}{|c|}{ rs12107036 G*mtDNA Cluster } \\
\hline$G$ * Others & 0,502 & 0,789 & 0,395 & 1,576 \\
\hline$G * T J$ & 0,158 & 0,647 & 0,353 & 1,185 \\
\hline$G * U K$ & $0,036^{\#}$ & 1,727 & 1,036 & 2,881 \\
\hline $\mathrm{G} * \mathrm{HV}$ & \multicolumn{4}{|c|}{ Reference } \\
\hline
\end{tabular}

mtDNA Clusters: haplogroups with a common phylogenetic origin BMI: Body Mass Index WOMAC: Western Ontario and McMaster Universities Osteoarthritis Index; OR: Odds Ratio; $\mathrm{Cl}$ : confidence interval; \#: statistical significance declared at $\mathrm{P} \leq 0.05$, in bold.

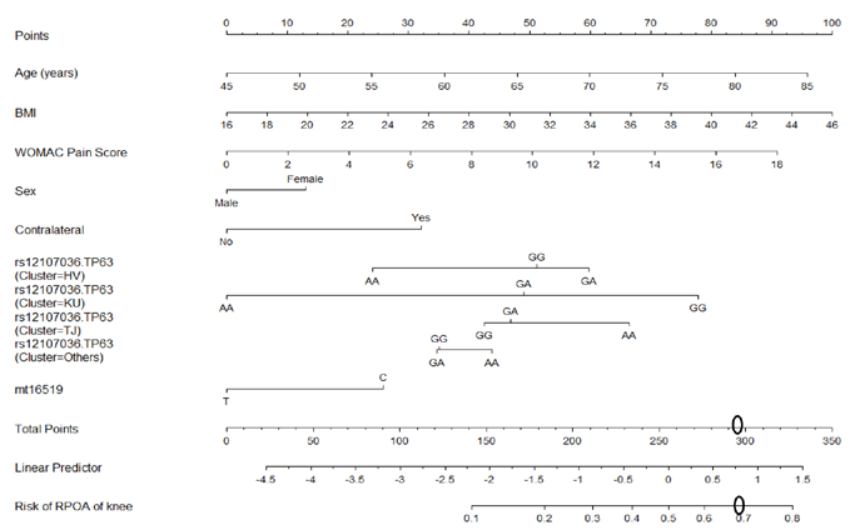

Image 1. Nomogran for the estimation of the risk of RPOA phenotype. Circles represent the values for the example. Clusters: haplogroups with a common phylogenetic origin BMI: Body Mass Index; WOMAC: Western Ontario and McMaster Universities Osteoarthritis Index.

Disclosure of Interests: None declared

DOI: 10.1136/annrheumdis-2021-eular.750

\section{POS0348 GENETIC SUSCEPTIBILITY VARIANTS FOR RHEUMATOID ARTHRITIS ARE NOT ASSOCIATED WITH EARLY REMISSION; A MULTI-COHORT STUDY}

S. Jurado Zapata ${ }^{1}$, M. Maurits ${ }^{1}$, Y. Abraham² ${ }^{2}$ E. Van den Akker ${ }^{3}$, A. Barton ${ }^{4}$, P. Brown ${ }^{5}$, A. Cope $^{6}$, I. González-Álvaro ${ }^{7}$, C. Goodyear ${ }^{8}$, A. van der Helm - van Mil ${ }^{1}$, X. $\mathrm{Hu}^{9}$, T. Huizinga ${ }^{1}$, M. Johannesson ${ }^{10}$, L. Klareskog ${ }^{10}$, D. Lendrem ${ }^{11}$, I. Mclnnes ${ }^{12}$ F. Morton ${ }^{12}$, C. Paterson ${ }^{12}$, D. Porter ${ }^{12}$, A. Pratt ${ }^{11}$, L. Rodriguez Rodriguez ${ }^{13}$,

D. Sieghart ${ }^{14}$, P. Studenic ${ }^{14}$, S. Verstappen ${ }^{4}$, L. Padyukov ${ }^{10}$, A. Winkler ${ }^{9}$, J. D. Isaacs ${ }^{5}$, 